\title{
Student Veteran perceptions of facilitators and barriers to achieving academic goals
}

\author{
Sonya B. Norman, PhD $;{ }^{1-4 *}$ Jay Rosen, PhD; ${ }^{1,3}$ Sara Himmerich, MA; ${ }^{1}$ Ursula S. Myers, MS ${ }^{5}$ Brittany Davis, \\ PhD; ${ }^{1}$ Kendall C. Browne, PhD; ${ }^{5}$ Neill Piland, PhD $^{6}$ \\ ${ }^{1}$ Department of Veterans Affairs (VA) San Diego Healthcare System, San Diego, CA; ${ }^{2}$ National Center for Posttrau- \\ matic Stress Disorder, Veterans Health Administration, White River Junction, VT; ${ }^{3}$ Department of Psychiatry, Univer- \\ sity of California, San Diego, San Diego, CA; ${ }^{4}$ Center of Excellence for Stress and Mental Health, VA San Diego \\ Healthcare System, San Diego, CA; ${ }^{5}$ San Diego State University/University of California, San Diego Joint Doctoral \\ Program in Clinical Psychology, San Diego, CA; ${ }^{6}$ Institute of Rural Health, Idaho State University, Boise, ID
}

\begin{abstract}
According to recent estimates, over 1 million Operation Iraqi Freedom/Operation Enduring Freedom Veterans are utilizing the post-9/11 GI Bill to pursue higher education. Data collected by the Department of Defense suggests that greater than $17 \%$ of returning Veterans may experience mental and physical health disorders, which can negatively affect school performance. The current study explored student Veterans' perceived facilitators and barriers to achieving academic goals. Thirty-one student Veterans completed self-report measures and interviews. Results suggested that Veterans who were reporting problems or symptoms in one mental or physical health domain were likely to be reporting symptoms or problems in others as well. The interview data were coded, and three overarching themes related to barriers and facilitators emerged: person features (e.g., discipline and determination, symptoms and stressors), institutional structure (i.e., what schools and the Department of Veterans Affairs do that was perceived to help or hinder student Veteran success), and policy concerns (i.e., how the structure of the GI Bill affects student Veteran school experience). Results from this research indicate the need for larger studies and program development efforts aimed at enhancing academic outcomes for Veterans.
\end{abstract}

Key words: GI Bill, interviews, mental health, military, OEF, OIF, posttraumatic stress disorder, reintegration, student, Veterans.

\section{INTRODUCTION}

Over 1 million Veterans who served in the conflicts in Iraq and Afghanistan (Operation Iraqi Freedom/Operation Enduring Freedom [OIF/OEF]) have accessed the education benefits of the most recent iteration of the GI Bill (Post-9/11 GI Bill) [1]. The Post-9/11 GI Bill was enacted by Congress in 2008 [2]. The main provisions of the act include funding 100 percent of a four-year undergraduate education, including tuition and other expenses

\footnotetext{
Abbreviations: AUDIT-C = Alcohol Use Disorders Identification Test-Consumption; HRQOL = Health Related Quality Of Life measure; M2C-Q = Military to Civilian Questionnaire; OIF/OEF = Operation Iraqi Freedom/Operation Enduring Freedom; PCL-6 = Posttraumatic Stress Disorder Checklist, Civilian-Abbreviated Version; PHQ-4 = Patient Health Questionnaire for Depression and Anxiety-Abbreviated Version; PTSD = posttraumatic stress disorder; $\mathrm{TBI}=$ traumatic brain injury; VA = Department of Veterans Affairs; VBA = Veterans Benefits Administration; VITAL = Veterans Integration to Academic Leadership.

*Address all correspondence to Sonya B. Norman, PhD; VA San Diego Healthcare System, 3350 La Jolla Village Dr (116B), San Diego, CA 92161; 858-642-3885; fax: 858-6423885. Email: snorman@ucsd.edu

http://dx.doi.org/10.1682/JRRD.2015.01.0013
} 
such as housing allowance. Federal expenditures on Veterans' education programs since the first GI Bill was funded in 2009 are estimated at \$34 billion [3].

Veteran education entitlements have benefit for former military servicemembers, academic institutions, and the general community. For Veterans, the completion of a postsecondary education is a significant developmental milestone offering self-determination and greater economic opportunities [4]. Employment among Veterans is associated with better overall psychological and physical well-being and participation in community life [5]. Student Veterans add to the diversity of campus culture [68]. Society benefits from the contributions made by educated Veterans to economic and social institutions [9]. Thus, understanding facilitators and barriers to the academic success of student Veterans is important to both the reintegration of Veterans following military service and to society as a whole.

Although a large number of Veterans pursue higher education, it is not clear how many complete a degree program. Data from the Million Records Project, a study of postsecondary academic outcomes of nearly 1 million student Veterans who utilized GI Bill benefits between 2002 and 2010, indicate that only half (51.7\%) graduated [1]. However, these data must be interpreted with caution because a portion of the sample was likely still in school working toward a degree. A completion rate of about half is comparable to rates of degree completion for nontraditional students overall (i.e., students who share characteristics such as delayed enrollment, having dependents, and attending school part-time) [10].

Although definitive information about the number of student Veterans who complete their degree program is not yet known, a number of qualitative and quantitative studies show that many student Veterans are facing extensive challenges in working toward their academic goals [11]. Challenges that have emerged include issues associated with being nontraditional students (e.g., significant age differences from peers), mental (e.g., posttraumatic stress disorder [PTSD], traumatic brain injury [TBI]) [12-15] and physical health problems [15-16] and perceived institution-policy inefficiencies in the implementation of the GI Bill's provisions (e.g., faculty and staff who are unfamiliar with military or Veteran culture) [17-21]. A qualitative study of 25 student Veterans identified self-perception of being a nontraditional student as a risk factor for not achieving academic goals [8]. Examples included difficulty blending into the student body, perceived negative perceptions toward Veterans by fellow students and faculty, and financial stress attributed to being an older student. In another qualitative study, student Veterans $(n=15)$ voiced difficulty adjusting to the loose structure of college life compared with life in the military and with having few social supports on campus [19]. Of note, some student Veterans perceived their nontraditional student status to be an advantage, noting that their military experiences prepared them for school by honing confidence, self-reliance, and discipline.

Veterans are at risk for PTSD and other mood disorders, substance use, TBI, and chronic pain [22-25]. These risks appear to be present for the subgroup of Veterans who return to school as well. Barry et al. examined mental health and substance use difference among three groups: student Veterans $(n=131)$, members of the Reserve Officer Training Corp $(n=38)$, and non-Veteran peers $(n=79)$ [26]. Student Veterans experienced the most PTSD symptoms. Symptoms of PTSD were positively related to alcohol use and alcohol-related consequences and negatively associated with grade point average across cohorts. Rudd et al. surveyed 628 members of a national advocacy group, Student Veterans of America, and nearly half (46\%) reported thinking about suicide and 20 percent had a plan [14]. PTSD symptoms were significantly related to suicide attempts and, overall, there was high prevalence of depression, anxiety, and PTSD symptoms. Many mental health problems, including PTSD, depression, and TBI, are associated with problems with attention, memory, and concentration, skills that are important to academic success [27]. Elliott et al. found that PTSD predicted perceived alienation on campus [13]. Smith-Osborne reported that when Veterans were treated for PTSD within the previous year, the odds of using the GI Bill to attend college were 2.14 times greater than among those who did not receive treatment [28]. Whiteman et al. conducted longitudinal electronic survey research comparing the development of social support for Veterans $(n=199)$ and their civilian counterparts $(n=181)$ [21]. Veterans reported less social support relative to their civilian counterparts. Social support was protective for both groups and related to achieving academic goals and improving mental health.

Perceived policy and institutional barriers may also impede student Veterans' achievement of academic goals. Persky and Oliver conducted mixed methods research with student Veterans $(n=60)$ [18]. Their participants noted that poor coordination among the various 
administrative processes involved in using the GI Bill, including school registration, course enrollment, financial aid, and counseling, was a significant stressor. Participants also expressed that their educational experience would be more positive if faculty and staff (i.e., counselors, advisors, campus mental health) were trained in military culture and Veteran-specific issues.

Understanding the experience of student Veterans can inform interventions designed to help Veterans achieve their academic goals and transition into civilian professional life. However, more information is needed regarding what student Veterans perceive to be barriers and facilitators to achieving their academic goals. The aim of this study was to better understand the experiences, particularly barriers and facilitators toward achieving academic goals, of student Veterans pursuing a higher education.

\section{METHODS}

Information regarding the study was disseminated to student Veterans through campus and student Veteran listservs, as well as through flyers posted on local campuses and community centers and at the local Department of Veterans Affairs (VA) hospital and outpatient clinics. Individuals who contacted study staff completed a brief telephone screen to ensure that they met eligibility criteria (i.e., enrollment in higher education including state and private colleges and universities, community colleges, technical schools, and online universities; current use of the GI Bill benefit; and military service during OIF/OEF). Once eligibility was confirmed, Veterans were invited to participate in a group interview. If necessary, participants were scheduled for individual interviews to accommodate idiosyncratic schedules. We initially planned to conduct only group interviews but added the option of individual interviews when it became clear that some Veterans were not able to attend interviews any times that other eligible participants could attend. Eligible individuals completed informed consent, including consent to be audio-recorded, brief self-report questionnaires, and an interview. Interviews were facilitated by study team members using a standardized list of interview questions. This study was approved by the University of California, San Diego Institutional Review Board and the VA San Diego Healthcare System
Research and Development Committee. Participants were compensated $\$ 30$ for their time.

\section{Participants}

Our goal was to recruit 30 to 35 participants so that we could balance capturing a diverse set of student Veteran experiences while also maintaining the ability to do indepth qualitative analyses [29-30]. We screened 46 potential participants. A total of 31 Veterans participated in the research study. Twenty-four Veterans participated in one of six focus groups, and seven participants were individually interviewed. Table 1 shows participant demographics.

\section{Measures}

Participants completed a demographic questionnaire asking about age, education, branch of service, number of deployments, time since last deployment, whether or not the participant had experienced a TBI, whether the Veteran had ever been diagnosed with a learning disability, and type of institution attending. In addition, Veterans completed a set of standardized, well-validated measures in order to characterize the sample: (1) the Health Related Quality of Life measure (HRQOL) [31], a 14item measure with a 7-point scale ranging from excellent to poor, to assess current quality of life; (2) the Posttraumatic Stress Disorder Checklist, Civilian-Abbreviated Version (PCL-6) [32], a 6-item screen for Diagnostic and Statistical Manual of Mental Disorders-4th Edition PTSD symptoms; (3) the Patient Health Questionnaire for Depression and Anxiety-Abbreviated Version (PHQ-4) [33] depression and anxiety screener; (4) the Alcohol Use Disorders Identification Test-Consumption (AUDIT-C) [34] to screen for problematic alcohol use; and (5) the Military to Civilian Questionnaire (M2C-Q) [35], a 16item measure to assess postdeployment community reintegration.

\section{Qualitative Interviews}

The research team developed an interview guide that included questions regarding experience on campus and in the classroom, logistics of using the GI Bill, and reasons for attending school. The guide included the following questions:

1. What was the most important reason for you to enroll in college after you left the military?

2. Describe your college experiences since you left the military.

a. What has worked well? 
Table 1.

Demographic characteristics $(N=31)$.

\begin{tabular}{|c|c|c|}
\hline Characteristic & $n$ & $\%$ \\
\hline \multicolumn{3}{|l|}{ Sex } \\
\hline Male & 29 & 93.6 \\
\hline Female & 2 & 6.4 \\
\hline \multicolumn{3}{|l|}{ Ethnicity } \\
\hline Non-Hispanic/Latino & 20 & 64.5 \\
\hline Hispanic/Latino & 6 & 19.4 \\
\hline Unreported & 5 & 16.1 \\
\hline \multicolumn{3}{|l|}{ Race } \\
\hline Caucasian & 13 & 41.9 \\
\hline African American/Black & 9 & 29.1 \\
\hline Biracial & 1 & 3.2 \\
\hline Unreported & 8 & 25.8 \\
\hline \multicolumn{3}{|l|}{ Education Level } \\
\hline High School Graduate & 6 & 19.4 \\
\hline Some College & 12 & 38.7 \\
\hline Associates Degree & 7 & 22.6 \\
\hline Bachelor's Degree & 3 & 9.7 \\
\hline Graduate/Professional School & 2 & 6.4 \\
\hline Unreported & 1 & 3.2 \\
\hline \multicolumn{3}{|l|}{ Branch of Service } \\
\hline Navy & 14 & 45.2 \\
\hline Marine Corps & 6 & 19.4 \\
\hline Air Force & 4 & 12.9 \\
\hline Army & 4 & 12.9 \\
\hline Coast Guard & 1 & 3.2 \\
\hline Unreported & 2 & 6.4 \\
\hline \multicolumn{3}{|l|}{ Number of Deployments } \\
\hline 0 & 2 & 6.4 \\
\hline 1 & 5 & 16.1 \\
\hline 2 & 11 & 35.5 \\
\hline 3 & 6 & 19.4 \\
\hline$\geq 4$ & 6 & 19.4 \\
\hline Unreported & 1 & 3.2 \\
\hline \multicolumn{3}{|l|}{ Type of Institution } \\
\hline 2 yr College & 16 & 51.6 \\
\hline 4 yr University & 10 & 32.3 \\
\hline For-Profit University & 5 & 16.1 \\
\hline \multicolumn{3}{|l|}{ Self-Reported Traumatic Brain Injury } \\
\hline No & 14 & 45.2 \\
\hline Yes & 15 & 48.4 \\
\hline Unreported & 2 & 6.4 \\
\hline Positive Screen on PCL-6 ( $\geq 14)$ & 13 & 41.9 \\
\hline Positive Screen on PHQ-4 ( $\geq 3)$ & 14 & 45.1 \\
\hline Positive Screen on AUDIT-C $(\geq 4)$ & 8 & 25.8 \\
\hline \multicolumn{3}{|c|}{$\begin{array}{l}\text { AUDIT-C = Alcohol Use Disorders Identification Test-Consumption; PCL-6 = } \\
\text { Posttraumatic Stress Disorder Checklist, Civilian-Abbreviated Version; PHQ-4 = } \\
\text { Patient Health Questionnaire for Depression and Anxiety-Abbreviated Version. }\end{array}$} \\
\hline
\end{tabular}

b. What have the challenges been?

3. What has helped you stick with school even though you face these challenges?

4. What specifically have you done to overcome some of the challenges?

5. What did you think going back to school would be like? What has met your expectations and what has surprised you?

6. Is campus culture "Veteran-friendly?” If so, how? If not, why?

7. What are your experiences with using campus disability services?

8. What are your experiences with the on-campus Veteran's service organizations?

9. What are your experiences with using the GI Bill?

10. What factors have affected your college experience?

11. Do you think you will complete school?

12. If you were talking to a Veteran who was just going back to school, what advice would you give the person? What would you warn them about? What encouragement would you give them?

\section{Characterizing Sample}

Demographics data and self-report measures (HRQOL, PCL-6, PHQ-4, AUDIT-C, M2C-Q) were entered into a database (SPSS version 22, IBM Corporation; Armonk, New York). Descriptive statistics were generated for both demographic characteristics and selfreport measures (Tables 1-2). Pearson correlations were used to examine the relationships between quality of life, symptoms of PTSD, symptoms of depression, drinking behaviors, and reintegration (Table 3).

\section{Interview Data Analysis}

The research team used a thematic analysis approach based on the work of Miles and Huberman [29]. Audio

Table 2.

Self-report measures.

\begin{tabular}{lcc}
\hline \multicolumn{1}{c}{ Measure } & Mean \pm SD & Range \\
\hline AUDIT-C & $1.68 \pm 2.04$ & $0-6$ \\
M2CQ & $31.29 \pm 15.94$ & $0-74$ \\
PCL-6 & $14.18 \pm 7.29$ & $6-28$ \\
PHQ-4 & $3.71 \pm 3.88$ & $0-12$ \\
\hline
\end{tabular}

AUDIT-C = Alcohol Use Disorders Identification Test-Consumption; $\mathrm{M} 2 \mathrm{C}-\mathrm{Q}=$ Military to Civilian Questionnaire; PCL-6 = Posttraumatic Stress Disorder Checklist, Civilian-Abbreviated Version; PHQ-4 = Patient Health Questionnaire for Depression and Anxiety-Abbreviated Version; SD = standard deviation. 
Table 3.

Self-report questionnaire Pearson correlations.

\begin{tabular}{lccccc}
\hline \multicolumn{1}{c}{ Measure } & M2CQ & PCL & AUDIT-C & PHQ & Quality of Life \\
\hline M2CQ & - & $0.811^{*}$ & 0.178 & $0.833^{*}$ & $-0.629^{*}$ \\
PCL-6 & $0.811^{*}$ & - & 0.346 & $0.906^{*}$ & $-0.713^{*}$ \\
AUDIT-C & 0.178 & 0.310 & - & 0.220 & -0.232 \\
PHQ-4 & $0.833^{*}$ & $0.906^{*}$ & 0.220 & $-0.673^{*}$ \\
Quality of Life & $-0.629^{*}$ & $-0.743^{*}$ & -0.232 & $-0.673^{*}$ & - \\
\hline
\end{tabular}

${ }^{*} p<0.001$.

AUDIT-C = Alcohol Use Disorders Identification Test-Consumption; M2C-Q = Military to Civilian Questionnaire; PCL-6 = Posttraumatic Stress Disorder Checklist, Civilian-Abbreviated Version; PHQ-4 = Patient Health Questionnaire for Depression and Anxiety-Abbreviated Version.

recordings of interviews were transcribed verbatim and proofread for accuracy. The transcripts were entered into Atlas.ti 7.0 (Berlin, Germany), a qualitative data analysis program, for the purposes of organization and analysis. Study team members reviewed the transcripts, and through a series of meetings, a set of descriptive codes was developed and defined. Using the descriptive codes, two researchers independently coded all of the group and individual interview transcripts. Reliability between the two researchers was assessed using blinded double-coding of 14 percent of the transcripts and resulted in 82.3 percent agreement between the two coders. The full sample of transcripts was reviewed and any discrepancies in coding were resolved through consensus meetings with the coders [36]. Broader themes emerged from the descriptive coding process. Descriptive codes were then categorized via these broader themes, or umbrella codes, which included (1) person positive, (2) person negative, (3) institution positive, (4) institution negative, (5) policy positive, and (6) policy negative.

\section{RESULTS}

\section{Quantitative Results}

Means and standard deviations of self-report measures are reported in Table 2. Table 3 shows that significant and moderate-to-strong relationships were noted among several measures. Namely, problems with reintegration were positively correlated with symptoms of PTSD, anxiety/ depression, and lower quality of life. PTSD symptoms, depression/anxiety symptoms, and lower quality of life were positively correlated with each other.

\section{Interview Results}

Focus group and interview data were categorized according to six umbrella codes that emerged from data analysis. The umbrella codes included person positive, person negative, institution positive, institution negative, policy positive, and policy negative. Results here and in Table $\mathbf{4}$ are organized by umbrella code.

\section{Person Factors}

Person positive. Participants voiced several person factors that positively affected their academic abilities. The majority of participants cited discipline $(n=20$, $64.5 \%)$ and organizational skills $(n=31,67.7 \%)$ developed during military service as helpful with the pursuit of higher education.

Perceived personal qualities such as being goal oriented and perseverance $(n=19,61.3 \%)$ were also reported as critical to academic readiness. Among those reporting goal orientation, some reported their motivation was enhanced by a desire to be the first in their family to earn a degree $(n=5,26.3 \%)$ or to use the degree as a way to achieve better means than they had growing up ( $n=5$, 26.3\%). Some expressed expectations of feeling a sense of accomplishment upon completing school $(n=17$, $54.8 \%)$ and achieving career goals $(n=25,80.6 \%)$.

Person negative. Veterans also voiced readiness for school and ability to assimilate into university life as potential barriers to finishing school. Reported personlevel obstacles to academic success included problems with physical and mental health ( $n=15,48.4 \%)$, worries that the Veteran did not have the skills to succeed in school ( $n=14,45.2 \%)$, and financial strain $(n=14$, 45.2\%). In addition, participants also reported that deployments while on Active Duty and activation of reserve units interrupted their academic progress.

\section{Institution Factors}

Institution positive. Participants characterized several features of academic settings as facilitators of academic success for Veterans seeking postsecondary 
Table 4.

Illustrative quotations and implications of themes.

\begin{tabular}{|c|c|c|}
\hline Theme & Example Quotes & Implication \\
\hline Person Positive & $\begin{array}{l}\text { "I mean, the accountability for being on time ... from the military } \\
\text { it's been outstanding. The work ethic from [the military], I mean } \\
\text { it's like second to none.” } \\
\text { "I focus on my school work. I go home and bang it out.” } \\
\text { "Between classes when we have break, I tend to find myself } \\
\text { reorganizing my whole backpack, like all the papers need to be } \\
\text { in the correct spot for history and everything.” } \\
\text { "Literally every single semester after I sign up for classes, I will go } \\
\text { into the Veterans office and I will [ask] 'did I forget something or } \\
\text { is there a piece of paper that I forgot to sign."” }\end{array}$ & $\begin{array}{l}\text { Train faculty/staff on how to recognize and } \\
\text { engage military skills in classroom and } \\
\text { school environment. } \\
\text { Provide resources to help Veterans apply } \\
\text { military skills to achieve academic goals. } \\
\text { Provide resources to help Veterans clarify } \\
\text { and commit to academic goals. } \\
\text { Increase availability and dissemination of } \\
\text { information about resources for mental } \\
\text { health and academic preparedness. } \\
\text { Facilitate access to physical and mental } \\
\text { health treatment. }\end{array}$ \\
\hline
\end{tabular}
up in, where all my friends didn't go to school, you know. . . . So, I'll just go to school to say I went to college and that's such a big thing for me, you know, and secondly, it's just, have a family and be able to provide."

"I wanted to graduate from college because my mother and father haven't."

"Just finishing that degree, I want to finish it you know for me, to actually accomplish it . . . so I will be able to say I did it.”

"I want to move forward, and accomplish my goal, you know, but I think that's the difference, is just the maturity. Where we've done it, and we've been through that, we lived through that phase, you know, I don't want that. I'm in school because I want to learn, not because I want to party.”

Institution Positive "One really nice thing though about being prior military, is that the early registration, it helps a lot.”

"I noticed a lot of Veterans are in the classroom so it makes me feel comfortable that I am not just the only one.”

Institution Negative "I hate everybody I go to school with. . . . It's like everyone we go to school with is a spoiled brat and 12 years old. It sucks."

"And I thought the VA office on campus would help you out a little bit more, than, fill out that sheet, fill out that sheet, fill out that sheet, leave me alone."

"The wait times when you call about your GI Bill are very long ... the [college, university] tells you to talk to the GI Bill people and then you are told to go back to your school for help by the GI Bill."

"When I first started at [school], I went to the Veterans office, and I said 'I am a disabled Veteran. Is there some place I'm supposed to go and fill out some paperwork and see if I can get some kind of disability [services]?' They said, 'Yeah, you can go and try, but it's a pain in the butt and there's a lot of paperwork to fill out, and it takes a long time for them to acknowledge that you're disabled.' I said, 'I'm not going to mess with it then.'”

"I think a lot of universities are not prepared to meet some of the challenges of our Veterans coming back. Specifically those who have multiple polytrauma issues, comorbidity issues, depression, PTSD. Coupled with substance use disorders.”
Make available Veteran-specific amenities (e.g., student Veteran lounge, early registration).

Show military-friendly symbols (e.g., flags, pro-military posters) around campus.

Train faculty and staff in military culture and Veteran issues.

Increase coordination between VBA and campuses.

Increase communication between VA facilities and school disability services to provide continuity of care.

Promote use of VITAL program.

Continue to disseminate the Veteran Campus Toolkit to assist with faculty and staff education on Veteran-specific issues. 
Table 4. (cont)

Illustrative quotations and implications of themes.

\begin{tabular}{|c|c|c|}
\hline Theme & Example Quotes & Implication \\
\hline$\overline{\text { Policy Positive }}$ & $\begin{array}{l}\text { "I want my degree, I want to work in the field that I've always } \\
\text { liked, so now I have the opportunity, and it's earned, because } \\
\text { nobody gave me this, this wasn't a free meal ticket. I did } 21 \text { years } \\
\text { in the service, so I earned it, and now I'm doing good use of it, } \\
\text { so yeah. Why waste it, you know?” } \\
\text { “And it's basically free money. And that was something that really } \\
\text { helped me just because I did not want to work, I just wanted to do } \\
\text { school full-time. And the GI Bill allows you to do that.” }\end{array}$ & $\begin{array}{l}\text { Create better system to explain GI Bill poli- } \\
\text { cies (e.g., no payment when class is not in } \\
\text { session) prior to start of school. } \\
\text { Improve coordination between VBA and } \\
\text { schools to reduce penalties (e.g., missed } \\
\text { tuition payments resulting in Veterans } \\
\text { being dropped from classes). } \\
\text { Increase use of social media to disseminate }\end{array}$ \\
\hline Policy Negative & $\begin{array}{l}\text { "Where it was every } 30 \text { days you get this ... now it goes off the } \\
\text { days that you're in school. So some months I get paid } \$ 1,820 \text {. } \\
\text { Some months I get a check for } \$ 400 \text { for the whole month, and } \\
\text { I'm not working, hence the As, because I focus on my school work.” } \\
\text { "Not being able to get paid my rent on time or get my books before } \\
\text { and I had an exam, I had almost two exams before I got my book. } \\
\text { Books are ridiculously expensive." }\end{array}$ & $\begin{array}{l}\text { information about deadlines and eligibil- } \\
\text { ity requirements. } \\
\text { Institute consistent payments throughout } \\
\text { calendar year. }\end{array}$ \\
\hline
\end{tabular}

education. Participants voiced appreciation of Veteranspecific academic services, including early class registration privileges and Veteran clubs ( $n=20,64.5 \%)$. Participants positively characterized the presence of an active Veterans community on campus, noting increased comfort in the context of others with a military background $(n=13,41.9 \%)$.

Institution negative. Some participants also reported frustration as they interacted with academic institutions and the Veterans Benefits Administration (VBA). Specifically, participants described frustrations related to their classroom experiences with younger, traditional students who were characterized as lacking discipline and comportment $(n=14,45.2 \%)$. Some participants $(n=13$, 41.9\%) reported frustration with both intrainstitution (i.e., registrar, academic advising, bursar) and interinstitution (i.e., VBA and colleges/universities) coordination of services and communication. Perceived poor coordination between when GI Bill funds were received and school deadlines contributed to problems with enrollment, course registration, and timely distribution of stipends and tuition. Participants also reported frustration with campus and VA representatives, who were characterized as unhelpful due to lack of knowledge and limited customer service skills ( $n=13,41.9 \%)$. Similarly, few participants reported positive experiences with on-campus disability services ( $n=4,12.9 \%$ ), and no participants reported accessing on-campus mental health services.

\section{Policy Factors}

Policy positive. More than half of student Veterans noted enhanced motivation to earn a degree in postsecondary education because of the availability of Veteran education benefits ( $n=16,51.6 \%)$. Participants also expressed satisfaction with the adequacy of the tuition and stipends allotments ( $n=14,45.2 \%)$.

Policy negative. Concern with late, uncertain, and variable stipend disbursement was prevalent and characterized as a significant challenge $(n=30,96.8 \%)$. Inconsistency and unpredictability of payments reportedly lead to financial difficulties. Participants voicing such concerns typically were using stipends as their principle means of supporting themselves and/or their families. Further, concerns with the timeliness of payments were substantiated by participants' reports of late tuition disbursement triggering automatic withdrawal from courses and difficulty purchasing books prior to the onset of the semester.

\section{DISCUSSION}

The goal of this study was to further understand perceived facilitators and barriers of achieving academic goals among student Veterans using the GI Bill. The positive correlations among the reintegration measure and the mental health screening measures suggest that students with elevated risk or symptoms in one domain were likely to have elevated risk or symptoms in other 
domains as well. Participant response to self-report measures indicated that just under half screened positive for clinically significant PTSD and depression symptoms. A quarter of participants reported alcohol use was in a range suggestive of alcohol misuse and just under half endorsed a history of TBI.

Given the small sample size and that some participants may have been recruited from flyers posted in VA mental health clinics, conclusions cannot be drawn regarding the prevalence of mental health problems among student Veterans. However, of note, none of our participants reported seeking mental health services or pursuing disability accommodations on campus. Participants reported that services were not available, cumbersome to access, or did not meet their needs. This finding suggests the importance of learning how and where student Veterans are willing to get mental health services and facilitating the availability of such services. We did not ask about seeking care outside of the campus, and it may be that Veterans were getting treatment at the VA or elsewhere in the community. However, given the noted time barrier, use of other services such as online and selfhelp programs should be explored. Many campuses now have links to VA mental health services through the Veterans Integration to Academic Leadership (VITAL) program [37-38]. This program was not available at the time we conducted our interviews, but our results support that such linkages may be important to helping student Veterans access care.

Themes in regard to person, institution, and policy factors emerged with facilitators and barriers noted for each theme. All participants described both facilitators and barriers to academic success. Person-level facilitators included discipline, organization, goal orientation/perseverance, and expectations of success in academic and vocational pursuits. Similar to other studies $[17,20]$, our findings suggest that Veterans perceive perspectives and skills acquired in the military such as goal orientation, time management, stress tolerance, a strong social network, and decorum to be facilitators of academic success. While Veterans were able to note that these qualities helped them deal with the challenges of school and helped them feel confident they would complete their degree, it was not clear whether campuses were engaging these strengths to help Veterans succeed. Several of our participants suggested training in military culture for faculty and staff would help Veterans succeed in school. One focus of such trainings could be to educate faculty and staff about the strengths and skills acquired in military service and how those can be fostered in the classroom and school environment.

Consistent with prior research, mental and physical health problems were perceived as barriers to achieving academic goals $[12,14]$. Most postdeployment mental health problems can be treated with evidence-based treatments [39], and prior research [28] suggests that those with mental health concerns who get treatment may be more likely to use the GI Bill. We do not know how many of our participants had sought or received treatment, but barriers such as lack of time may have kept participants from engaging in treatment. As mentioned previously, programs to facilitate the process of getting treatment for student Veterans, such as the VITAL program [37-38], may help students to succeed in school. Several participants noted that they did not believe they had the skills to succeed academically. Academic readiness classes are available at some VA facilities, helping Veterans prepare to sit through classes, take notes, study for exams, etc. Greater availability of such classes, perhaps by offering them online, and perhaps better dissemination of information about available resources, may help Veterans feel more confident and prepared to succeed in school.

In regard to institution factors, participants reported positive experiences when campuses offered Veterancentric services such as priority registration and Veteranspecific academic and financial counselors. Similarly, campuses supportive of military culture through a visible presence of other Veterans and Veteran-specific cocurricular activities (i.e., Veterans' lounge, Veterans' clubs) were positively characterized by participants. Even symbols of a Veteran-friendly campus, such as displays of flags or pro-military posters were noted by some participants as making the campus a more comfortable place. Some participants who reported that they did not take part in Veteran activities on campus still appreciated that they were present. These reported facilitators again highlight the perceived benefits of understanding unique factors related to the needs of Veterans and of military culture. Training in these issues is readily available online, for example through the Veteran Campus Toolkit [40], and our results suggest faculty and staff who work with student Veterans should be encouraged to complete this training.

Institutional barriers included difficulties fitting into the campus community given perceived discrepancies between Veterans and typical college students in regard to 
age, maturity level, and values in regard to timeliness and classroom decorum. This is consistent with prior studies where student Veterans reported not fitting into campus culture as a barrier [21]. Whether these beliefs are unique to student Veterans or overlap with barriers experienced by nontraditional students more broadly is not clear. Our sample did have demographic similarities with other nontraditional students [41]. Namely, participants tended to be older, with some first-generation college students, and with a high representation of diverse ethnic and racial groups.

Participants regarded the GI Bill as a positive, motivating factor in their pursuit of a higher education degree and voiced the importance of the policy in helping their transition into civilian life. While some participants felt supported by the stipend, others, typically participants who were using the stipend as their main source of income, reported concerns with the disbursement schedule of the stipend. In particular, participants perceived that having equal disbursement schedules of their stipends throughout the year, rather than higher disbursements on months when there were more days of school and lower on months when there were breaks, would be far less stressful. Similarly, some participants reported delays in disbursement of tuition benefits to their institutions resulted in academic obstacles. Other frustration related to the implementation of the GI Bill included perceived poor coordination between academic institutions and VBA resulting in missed tuition payments and automatic withdrawal from coursework. Similarly, participants reported frustrations with both academic counselors and VBA representatives, who they perceived as lacking knowledge of GI Bill benefits and program requirements.

Thus, while overall the GI Bill was seen as a positive and beneficial program for Veterans, important practical barriers that caused significant stress were noted. Most participants noted that they did not fully understand the complexities of the GI Bill and the payment policy until they were already in school. A system to better explain the GI Bill and associated policies prior to beginning school may help Veterans better prepare for school and meet their academic goals. If Veterans understand the components of the program, its financial structure and the monetary benefits it provides, requirements for continuing eligibility, and where to go for information and assistance, they may feel less overwhelmed. Communication technologies and social media may facilitate this process. More seasoned student Veterans that act as mentors on campus may also be helpful, similar to the peer-support specialist roles used in the VA healthcare system. Our participants were clear that varying payments based on number of days that they were in school per month was one of their greatest stressors in their school experience. Continuous and unambiguous stable support may be a factor that would help many complete their academic goals.

Limitations of this exploratory study include a small number of participants, mostly male, residing in a single city; however, a variety of secondary institutions were represented, including community colleges, 4 yr universities, and for-profit institutions. We did not ask participants about their use and perception of specific campus and VBA resources. Some students were interviewed individually and some in groups. This allowed us to include a larger number of student Veterans but resulted in more variability in study procedures. A longitudinal study that measures individual, institutional, and policy facilitators and barriers would be the next step to understanding the student Veteran experience and to proposing programs and policies to help student Veterans with the challenges they face.

\section{CONCLUSIONS}

Our findings substantiate the wealth of commentaries indicating that Veterans represent a unique campus cohort who may benefit from tailored academic services and institution supports to acclimate to campus life $[7,27]$. However, within our small sample, we identified a great deal of diversity in opinions and reactions to particular barriers and facilitators. For example, in a discussion of how difficult it was to tolerate young traditional students sometimes, one Veteran expressed that these other students made him so angry he did not want to go back to class, while another expressed how he would never let "those kids" keep him from achieving his goals.

Some of the variability we witnessed in our sample included (1) Veterans who felt highly motivated and prepared, (2) Veterans who felt they needed additional preparation to succeed in school, and (3) those who expressed that physical and or mental/emotional challenges interfered with school performance. It appears that there is no one-size-fits-all solution that would help all student Veterans achieve their academic goals. Rather, a number and variety of Veteran-centered programs and policies may 
improve the rates of student Veterans achieving their academic goals. For example, easier logistics of coordinating among agencies involved in the GI Bill may help some, while a more welcoming campus culture or more opportunity to learn skills for academic success may be of more help to others. The incremental support offered by removing individual barriers and adding more facilitators may prove helpful to increasing overall rates of students achieving academic goals. Ideally, schools would design and implement programs that are flexible to respond effectively to the needs of students as they move along in their educational and career paths. These needs may change over time, and what was effective for a new student may not be helpful for the same student in ensuing time periods. Both the general program (policy) and institutional response should be capable of evolving over time.

\section{ACKNOWLEDGMENTS}

\section{Author Contributions:}

Study design: S. B. Norman, J. Rosen, S. Himmerich, U. S. Myers, B. Davis, K. C. Browne, N. Piland.

Analysis of data: S. B. Norman, J. Rosen, S. Himmerich, U. S. Myers, B. Davis, K. C. Browne, N. Piland.

Manuscript preparation: S. B. Norman, J. Rosen, S. Himmerich, U. S. Myers, B. Davis, K. C. Browne, N. Piland.

Financial Disclosures: The authors have declared that no competing interests exist.

Funding/Support: This material was based on work supported by the Veterans Medical Research Foundation to Dr. Norman with additional support from the VA Health Services Research and Development Substance Use Disorder Quality Enhancement Research Initiative.

Additional Contributions: We would like to thank Kerstin Lynam for her support of this project. Dr. Browne is now at the Mental Illness Research, Education and Clinical Center, VA Puget Sound Health Care System and Department of Psychiatry \& Behavioral Sciences, University of Washington.

Institutional Review: This study was approved by the University of California, San Diego Institutional Review Board and the VA San Diego Healthcare System Research and Development Committee, and participants provided informed consent.

Participant Follow-Up: The authors do not plan to inform participants of the publication of this study.

\section{REFERENCES}

1. Cate CA. An examination of student veteran completion rates over service eras: An in-depth analysis of the 2010 National Survey of Veterans. Student Veterans of America. 2014;2(1):1-5.
2. Title V of the Supplemental Appropriations Act of 2008, H.R. 2642, 110th U.S. Cong. (2008).

3. Roulo C. Millionth Post-9/11 GI Bill recipient announced. Washington (DC): Department of Defense News; 2013.

4. Teachman J. Military service and educational attainment in the all-volunteer era. Sociol Educ. 2007;80(4):359-74. http://dx.doi.org/10.1177/003804070708000404

5. Resnick SG, Rosenheck RA. Posttraumatic stress disorder and employment in veterans participating in Veterans Health Administration Compensated Work Therapy. J Rehabil Res Dev. 2008;45(3):427-35. [PMID:18629751] http://dx.doi.org/10.1682/JRRD.2007.06.0093

6. Branker C. Deserving design: The new generation of student veterans. J Postsecondary Education Disabil. 2009; 22(1):59-66.

7. Ackerman R, DiRamio D, editors. Creating a veteranfriendly campus: Strategies for transition success. Hoboken (NJ): John Wiley and Sons; 2009.

8. DiRamio D, Ackerman R, Mitchell RL. From combat to campus: Voices of student-veterans. NASPA J. 2008;45(1): 73-102.

9. Altschuler G, Blumin S. The GI Bill: The new deal for veterans. New York (NY): Oxford University Press; 2009.

10. U.S. Department of Education. Nontraditional undergraduates, NCES 2002-12. Washington (DC): National Center for Education Statistics; 2002.

11. Barry AE, Whiteman SD, Wadsworth SM. Student service members/veterans in higher education: A systematic review. J Stud Aff Res Pract. 2014;51(1):30-42.

http://dx.doi.org/10.1515/jsarp-2014-0003

12. Barry AE, Whiteman SD, MacDermid Wadsworth SM. Implications of posttraumatic stress among military-affiliated and civilian students. J Am Coll Health. 2012;60(8):562-73. [PMID:23157198] http://dx.doi.org/10.1080/07448481.2012.721427

13. Elliott M, Gonzalez C, Larsen B. U.S. military veterans transition to college: Combat, PTSD, and alienation on campus. J Stud Aff Res Pract. 2011;48(3):279-96. http://dx.doi.org/10.2202/1949-6605.6293

14. Rudd MD, Goulding J, Bryan CJ. Student veterans: A national survey exploring psychological symptoms and suicide risk. Prof Psychol Res Pr. 2011;42(5):354-60. http://dx.doi.org/10.1037/a0025164

15. Widome R, Laska MN, Gulden A, Fu SS, Lust K. Health risk behaviors of Afghanistan and Iraq war veterans attending college. Am J Health Promot. 2011;26(2):101-8. [PMID:22040391] http://dx.doi.org/10.4278/ajhp.090826-QUAN-278

16. Whiteman SD, Barry AE. A comparative analysis of student service member/veteran and civilian student drinking motives. J Stud Aff Res Pract. 2011;48(3):297-313. 


\section{[PMID:22328965]}

http://dx.doi.org/10.2202/1949-6605.6322

17. DiRamio D, Jarvis K. Special issue: Veterans in higher education-When Johnny and Jane come marching to campus. ASHE High Educ Rep. 2011;37(3):1-144.

18. Persky KR, Oliver DE. Veterans coming home to the community college: Linking research to practice. Community Coll J Res Pract. 2010;35(1-2):111-20. http://dx.doi.org/10.1080/10668926.2011.525184

19. Livingston WG, Havice PA, Cawthon TW, Fleming DS. Coming home: Student veterans' articulation of college reenrollment. J Stud Aff Res Pract. 2011;48(3):315-31. http://dx.doi.org/10.2202/1949-6605.6292

20. Rumann CB, Hamrick FA. Student veterans in transition: Re-enrolling after war zone deployments. J Higher Educ. 2010;81(4):431-58. http://dx.doi.org/10.1353/jhe.0.0103

21. Whiteman SD, Barry AE, Mroczek DK, Macdermid Wadsworth S. The development and implications of peer emotional support for student service members/veterans and civilian college students. J Couns Psychol. 2013;60(2): 265-78. [PMID:23421774] http://dx.doi.org/10.1037/a0031650

22. Van der Kolk BA, McFarlane AC, Weisaeth L. Traumatic stress: The effects of overwhelming experience on mind, body, and society. New York (NY): Guilford Press; 2012.

23. Milliken CS, Auchterlonie JL, Hoge CW. Longitudinal assessment of mental health problems among active and reserve component soldiers returning from the Iraq war. JAMA. 2007;298(18):2141-48. [PMID:18000197] http://dx.doi.org/10.1001/jama.298.18.2141

24. Tanielian TL, Jaycox L. Invisible wounds of war: Psychological and cognitive injuries, their consequences, and services to assist recovery. Vol 1. Santa Monica (CA): Rand Corporation; 2008.

25. Terrio HP, Nelson LA, Betthauser LM, Harwood JE, Brenner LA. Postdeployment traumatic brain injury screening questions: Sensitivity, specificity, and predictive values in returning soldiers. Rehabil Psychol. 2011;56(1):26-31. [PMID:21401283] http://dx.doi.org/10.1037/a0022685

26. Barry AE, Whiteman S, Wadsworth SM, Hitt S. The alcohol use and associated mental health problems of student service members/veterans in higher education. Drugs Educ Prev Policy. 2012;19(5):415-25. http://dx.doi.org/10.3109/09687637.2011.647123

27. American College on Education. Accommodating student veterans with traumatic brain injury and post traumatic stress disorder [Internet]. Washington (DC): American College of Education; 2014. Available from: http:// www.acenet.edu/news-room/Pages/AccommodatingStudent-Veterans-with-Traumatic-Brain-Injury-and-PostTraumatic-Stress-Disorder.aspx
28. Smith-Osborne A. Mental health risk and social ecological variables associated with educational attainment for Gulf War veterans: Implications for veterans returning to civilian life. Am J Community Psychol. 2009;44(3-4):327-37. [PMID:19838786]

http://dx.doi.org/10.1007/s10464-009-9278-0

29. Miles MB, Huberman AM. Qualitative data analysis: An expanded sourcebook. Thousand Oaks (CA): Sage; 1994.

30. Sandelowski M. Sample size in qualitative research. Res Nurs Health. 1995;18(2):179-83. [PMID:7899572] http://dx.doi.org/10.1002/nur.4770180211

31. Zahran HS, Kobau R, Moriarty DG, Zack MM, Holt J, Donehoo R. Health-related quality of life surveillanceUnited States, 1993-2002. In: Centers for Disease Control Prevention Morbidity and Mortality Weekly Report. Atlanta (GA): CDC; 2005. p. 1-35.

32. Lang AJ, Stein MB. An abbreviated PTSD checklist for use as a screening instrument in primary care. Behav Res Ther. 2005;43(5):585-94. [PMID:15865914] http://dx.doi.org/10.1016/j.brat.2004.04.005

33. Löwe B, Wahl I, Rose M, Spitzer C, Glaesmer H, Wingenfeld K, Schneider A, Brähler E. A 4-item measure of depression and anxiety: Validation and standardization of the Patient Health Questionnaire-4 (PHQ-4) in the general population. J Affect Disord. 2010;122(1-2):86-95.

[PMID:19616305]

http://dx.doi.org/10.1016/j.jad.2009.06.019

34. Saunders JB, Aasland OG, Babor TF, de la Fuente JR, Grant M. Development of the Alcohol Use Disorders Identification Test (AUDIT): WHO collaborative project on early detection of persons with harmful alcohol consumption-II. Addiction. 1993;88(6):791-804. [PMID:8329970] http://dx.doi.org/10.1111/j.1360-0443.1993.tb02093.x

35. Sayer NA, Frazier P, Orazem RJ, Murdoch M, Gravely A, Carlson KF, Hintz S, Noorbaloochi S. Military to civilian questionnaire: A measure of postdeployment community reintegration difficulty among veterans using Department of Veterans Affairs medical care. J Trauma Stress. 2011; 24(6):660-70. [PMID:22162082]

http://dx.doi.org/10.1002/jts.20706

36. Wisdom JP, Green CA. "Being in a funk": Teens' efforts to understand their depressive experiences. Qual Health Res. 2004;14(9):1227-38. [PMID:15448297] http://dx.doi.org/10.1177/1049732304268657

37. McCaslin S, Thiede J, Vinatieri T, Passi H, Bull Lyon K, Ahern DA, Armstrong K, Chitaphong K. Facilitating Veterans' Academic Success: Veterans Integration to Academic Leadership (VITAL). Career Plann \& Adult Dev. 2014;30: 191-209.

38. Veterans Integration to Academic Leadership (VITAL) [Internet]. Washington (DC): Department of Veterans Affairs; 2014 [cited 2014 Jan 5; updated 2015 Aug 14]; 
JRRD, Volume 52, Number 6, 2015

Available from: http://www.nyharbor.va.gov/services/ vital.asp

39. VA/DoD clinical practice guidelines: Management of posttraumatic stress disorder and acute stress reaction. Washington (DC): Department of Veterans Affairs; 2010.

40. VA Campus Toolkit [Internet]. Washington (DC): Department of Veterans Affairs; 2014 [cited 2015 Jan 5]. Available from: http://www.mentalhealth.va.gov/studentveteran/

41. National Center for Education Statistics. Nontraditional undergraduates / Definitions and data [Internet]. Washington (DC): Department of Education; 2014. Available from: http://nces.ed.gov/pubs/web/97578e.asp

Submitted for publication January 25, 2015. Accepted in revised form March 31, 2015.
This article and any supplementary material should be cited as follows:

Norman SB, Rosen J, Himmerich S, Myers US, Davis B, Browne KC, Piland N. Student Veteran perceptions of facilitators and barriers to achieving academic goals. J Rehabil Res Dev. 2015;52(6):701-12.

http://dx.doi.org/10.1682/JRRD.2015.01.0013

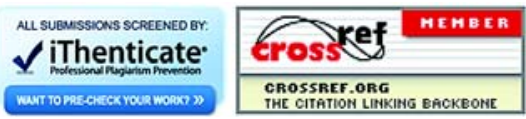

